\title{
Discurso e ideologia: um estudo de caso com dois professores de inglês da escola pública
}

\section{Paula Telles da Costa Fernandes}

Doutoranda em Linguística Aplicada e Estudos da

Linguagem na PUC-SP - Pontifícia Universidade

Católica de São Paulo; São Paulo; São Paulo;

Brasil.

paulafern@uol.com.br

Resumo: 0 presente artigo tem por objetivo estabelecer a relação entre os conceitos de discurso e ideologia e demonstrar como a ideologia se manifesta no discurso de dois professores de inglês da escola pública. Os conceitos de discurso e ideologia são examinados a partir do aporte teórico proposto por Bakhtin e o Círculo e os dados utilizados neste artigo estão embasados nas entrevistas com dois professores de inglês de uma escola pública estadual da cidade de São Paulo. As ideologias presentes no discurso dos professores evidenciam a não realização na profissão. Por meio de seus dizeres, os professores, mesmo fluentes no idioma, não escolheram a profissão que exercem e não acreditam que a escola pública seja o lugar onde se aprende inglês.

Palavras-chaves: Discurso; Ideologia; Ensino de inglês como língua estrangeira
Abstract: This article aims at presenting the relations between the concepts of discourse and ideology and demonstrate the ideological aspects raised in the teachers' discourse. The concepts of discourse and ideology as applied in this paper stem from Bakhtin \& The Circle and the data are based on interviews that were carried out with two english teachers from a São Paulo State Public School. The ideologies present in the teachers' discourse expose a lack of professional fulfillment. Although fluent in English, the teachers demonstrate through their discourse that they did not choose their profession and that they do not believe that English learning can take place in the public school.

Keywords: Discourse, Ideology, English teaching as a foreign language 

Este artigo tem por objetivo estabelecer dois conceitos fundamentais presentes na teoria bakhtiniana, o conceito de discurso e o conceito de ideologia. Esses conceitos serão examinados a partir de diferentes obras de Bakhtin e o Círculo ${ }^{1}$. Em seguida, com o objetivo de demonstrar como a ideologia se manifesta no discurso, apresento dados coletados no ano de 2009 a partir de entrevistas com dois professores de inglês de uma escola pública estadual situada na zona leste da cidade de São Paulo. Este artigo apresenta resultados parciais de uma pesquisa de mestrado desenvolvida em uma abordagem inter/transdisciplinar que abrange questões da Linguística Aplicada (LA) e da Educação. Foi delineada com o objetivo de investigar os aspectos ideológicos relacionados ao ensinoaprendizagem de inglês como língua estrangeira na escola pública. A fim de investigar esses aspectos, entrevistei, no mês de maio de 2009 dois professores de inglês de uma escola pública estadual situada na zona leste da cidade de São Paulo. O distrito em que está situada a escola, de acordo com o censo de 2010, tem uma população de 96.441 habitantes e renda média por habitante de R\$1.345,63. É a região mais desenvolvida da zona leste da cidade, com melhor urbanização, verticalização e infra-estrutura.

A escola em que foi realizada a pesquisa é considerada tradicional no distrito e tem aproximadamente 1.200 alunos dos ensinos fundamental e médio. Além disso, no ano de 2008, a escola foi classificada entre as cinco melhores escolas do Estado de São Paulo, segundo o SARESP (Sistema de Avaliação de Rendimento Escolar do Estado de São Paulo). Na escola, há uma sala com telão e projetor (sala multimídia), quadra de esportes, cantina e salas de aula em bom estado de limpeza, com lousa, carteiras e mesa para o professor. Os participantes da pesquisa são Ana (professora-participante), Rui (professor-participante)
${ }^{1}$ Segundo Zandwais (2009), o Círculo de Bakhtin era constituído por um grupo de amigos, oriundos inicialmente da escola de Nevel, VALENTIN VOLOSHINOV (18351936), MIKHAIL

BAKHTIN (1895-1975), LEV PUMPIANSKII (1891-1940) e MATVEI KAGAN (1889-1937), que se amplia a partir de 1920, quando Mikhail Bakhtin é transferido para Vitebsk, recebendo outras figuras ilustres como PAVEL MEDVEDEV (18911938). Zandwais (2009) lembra que esse grupo se reunia informalmente, à semelhança da maioria dos intelectuais bolcheviques da época, com vistas a produzir conhecimentos científicos sobre Filologia, Filosofia, Literatura, Arte, Biologia e Linguística. Além disso, a concepção de ciência russo-soviética sempre foi dominantemente holística, isto é, fundada em torno das investigações interdisciplinares, de tal modo que o desenvolvimento dos estudos sobre a linguagem foi realizado de forma articulada, sobretudo, entre domínios de áreas de conhecimento distintas, tais como a Psicologia Social, a Filosofia, a História, a Paleontologia e a Biologia. 
${ }^{2}$ Os professoresparticipantes são identificados por nomes fictícios sendo que o gênero (feminino e masculino) é mantido. e eu (professora-pesquisadora). ${ }^{2} \mathrm{Na}$ época da geração de dados, Ana estava com 28 anos, cursava o mestrado na área de Linguagem e Educação e era professora do último ciclo do ensino fundamental. Rui estava com 33 anos e dava aulas para as três séries do ensino médio. Ana e Rui são fluentes em inglês.

É preciso esclarecer que a partir da análise das entrevistas dos dois professores busco explicitar as ideologias ou visões (irrefletidas ou não) sobre o ensino-aprendizagem de inglês manifestadas em seus discursos. Essas ideologias legitimam uma postura ideológica presente na nossa sociedade, ou seja, as visões presentes no discurso dos professores correspondem ao discurso presente na sociedade de desvalorização da profissão docente e da escola pública como espaço de aprendizagem de inglês. Por meio de seus dizeres os professores-participantes, mesmo fluentes no idioma, não escolheram a profissão que exercem e não acreditam que a escola pública seja o lugar onde se aprende inglês.

Outros estudos, realizados em diferentes estados brasileiros a respeito do ensino de inglês na escola pública, confirmam "o quadro desalentador do ensinoaprendizagem de inglês na escola pública” (COX e ASSISPETERSON 2007, p. 17). O estudo de Dias (2006), por exemplo, deteve-se na análise de crenças de atores sociais da esfera escolar e familiar em uma escola pública de periferia. Os resultados mostraram que a descrença no ensino de inglês realizado pela escola pública é recorrente entre os atores dos dois contextos.

Depoimentos de participantes da pesquisa de Barcelos (2006), alunos de escola pública, já na universidade, relatam histórias sofridas de suas dificuldades para aprender inglês, apesar da escola. Completam o quadro desalentador depoimentos de participantes da pesquisa de Santos (2006, p. 127) que caracterizam o professor de língua estrangeira da escola pública como "um professor que não é de verdade", um ser invisível, cuja "ausência é menos percebida”. 
Procuro demonstrar neste artigo que o discurso dos professores-participantes desta pesquisa vem confirmar o quadro desanimador do ensino do inglês como língua estrangeira nas escolas públicas. Ao proceder à análise, procuro trazer para a discussão resultados apontados em pesquisas recentes tanto na área do Ensino de Línguas Estrangeiras como na área de Educação.

No entanto, antes de analisar o discurso dos professores apresento os conceitos teóricos que embasam este artigo.

\section{Discurso e ideologia}

Em O discurso em Dostoievski, Bakhtin define o discurso como "a língua em sua integridade concreta e viva e não a língua como objeto específico da linguística, obtido por meio de uma abstração absolutamente legítima e necessária de alguns aspectos da vida concreta do discurso" (BAKHTIN, 2008, p. 207).

Em texto escrito posteriormente e também à respeito do conceito de discurso Bakhtin (2006) afirma “... o discurso só pode existir de fato na forma de enunciações concretas de determinados sujeitos falantes, sujeitos do discurso. O discurso sempre está fundido em forma de enunciado pertencente a um determinado sujeito do discurso, e fora dessa forma não pode existir" (BAKHTIN, 2006, p. 274).

Observa-se que o conceito de discurso está intrinsecamente ligado à língua em sua integridade concreta e viva. Para Bakhtin, o discurso só existe em forma de enunciado concreto pertencente a um determinado sujeito.

Uma característica fundamental de toda obra de Bakhtin e o Círculo fica clara a partir dos trechos citados. Os conceitos que balizam a teoria bakhtiniana encontram-se interligados e não podem ser concebidos 
de forma dissociada. O conceito de discurso não pode ser entendido se não a partir do conceito de enunciado concreto. O mesmo se dá com toda obra de Bakhtin e o Círculo, todos os conceitos desenvolvidos devem ser vistos de forma a constituirem um sistema, também chamado de arquitetônica ou arquitetura bakhtiniana. Arrisco dizer que os conceitos que formam a arquitetônica ou arquitetura bakhtiniana não devem ser vistos como pilares, já que os pilares de uma casa ou edifício podem ser construídos separadamente. Os conceitos bakhtinianos não podem ser construídos separadamente, tendo em vista que estão interligados.

A partir dessa visão sistêmica da teoria, Bakhtin/ Medvedev (1991) afirmam ser "impossível entender o enunciado concreto sem que alguém se familiarize com seus valores, sem entender a orientação de sua avaliação no ambiente ideológico" (BAKHTIN/MEDVEDEV, 1991, p. 121 - tradução minha). Dessa forma, os discursos implicam sempre uma manifestação ideológica, aqui entendida como visão de mundo constituída no plano sócio-histórico.

De acordo com Amorim (2004), na maioria dos escritos de Bakhtin, o termo ideologia designa simplesmente um ponto de vista, uma visão de mundo e as criações ideológicas estão presentes em todas as sociedades, mesmo as que se organizam de modo diverso das sociedades capitalistas.

Amorim (2004) afirma:

Visão que não é individual, mas cuja natureza social não se define necessariamente por uma relação de classes. Ela é própria a cada grupo social e sua especificidade pode ser de classe, mas também de profissão ou geração. Uma voz é sempre ideológica porque ela traz um ponto de vista constituído num determinado lugar e não em outro (AMORIM, 2004, p. 143). 
A ideologia em Bakhtin não tem nada do conceito marxista: efeito de ilusão ou alienação que se produz como mascaramento necessário à dominação de classe. A autora acrescenta:

Mesmo quando o termo ideologia se insere explicitamente numa problemática marxista, ele está longe de adquirir a significação do conceito correspondente. [...] A luta de classes e as condições de produção são elementos determinantes da ideologia, mas nem por isso ela é pensada como falsa consciência ou efeito de alienação (AMORIM, 2004, p.144).

Miotello (2005) acredita que Bakhtin e o Círculo aprofundaram questões que Marx e Engels apenas haviam tocado. As questões que tratam do estudo da ideologia, conceito fundamental no pensamento bakhtiniano, estão abordadas de forma mais ampla e aprofundada no livro Marxismo e filosofia da linguagem ${ }^{3}$ e também no livro Problemas da poética de Dostoiévski, e ainda se acham espalhadas em todos os escritos atribuídos ao Círculo. A questão abordada pelos membros do Círculo era a de que a produção teórica marxista, até aquele momento, não havia colocado o problema do estudo da ideologia no lugar certo (MIOTELLO, 2005, p. 167).

Segundo Miotello (2005), a única definição de ideologia dada por alguém do Círculo pertence a Voloshinov (apud MIOTELLO, 2005), no texto Que é a linguagem?, de 1930.

Por ideologia entendemos todo o conjunto dos reflexos e das interpretações da realidade social e natural que tem lugar no cérebro do homem e se expressa por meio de palavras [...] ou outras formas sígnicas (MIOTELLO, 2005, p.169).

Ao pensar o conceito de ideologia como uma visão de mundo, considera-se a sua constituição social e
${ }^{3}$ Zandwais (2009) observa que a autoria do texto de Marxismo e Filosofia da Linguagem tem sido objeto de discussão por muitos estudiosos que realizaram inúmeros artigos em torno dessa questão.

Alguns afirmam, categoricamente, que o autor é Voloshinov, mas outros ainda não estão convencidos. A autora ressalta que em russo, espanhol e inglês a obra aparece sob a assinatura de Voloshinov

(ZANDWAIS, 2009, p. 97). 
histórica, que não pode ser reduzida nem à sua superfície empírica (como se fosse um rol de meros fenômenos isolados), nem fechada e autocontida no mundo de uma consciência individual ou no reino das "puras ideias" (FARACO, 2009, p. 48).

Pelo seu caráter intrinsecamente sócio-histórico, a criação ideológica exige, para ser estudada, um conceitual e um método de natureza sociológica, para cujo delineamento ele se propõe contribuir. Nesse processo, [...] todos os produtos da criação ideológica são dotados de materialidade, isto é, são parte concreta e totalmente objetiva da realidade prática dos seres humanos (não se podendo estudá-los, portanto, desconectados dessa realidade) (FARACO, 2009, p. 48).

Com relação aos discursos, pode-se afirmar que eles não estão imunes à ideologia: ela sempre os determina e determina a todos, inclusive aqueles que pretendem ser objetivos, tais como os discursos científicos.

O valor exemplar, a representatividade da palavra como fenômeno ideológico e a excepcional nitidez de sua estrutura semiótica já deveriam nos fornecer razões suficientes para colocarmos a palavra em primeiro plano no estudo das ideologias (BAKHTIN/VOLOSHINOV, 2009, p.36).

A palavra, pode funcionar sempre como um signo neutro enquanto língua abstrata, objeto de investigação da Filologia, dos dicionários e dos estudos linguísticos não sociológicos. Enquanto objeto da práxis concreta, entretanto, está sempre carregada de valores, que permitem compreender sua função ideológica (ZANDWAIS, 2009).

Referindo-se ao conceito de signo ideológico Faraco (2009) aponta no mesmo sentido que Zandwais (2009): 
[...] para o Círculo (de Bakhtin), a significação dos enunciados tem sempre uma dimensão avaliativa, expressa sempre um posicionamento social valorativo. Desse modo, qualquer enunciado é, na concepção do Círculo, sempre ideológico para eles, não existe enunciado não-ideológico. É ideológico em dois sentidos: qualquer enunciado se dá na esfera de uma das ideologias (i.e., no interior de uma das áreas da atividade intelectual humana) e expressa sempre uma posição avaliativa (i.e., não há enunciado neutro; a própria retórica da neutralidade é também uma posição axiológica) (FARACO, 2009, p. 47).

Bakhtin/Voloshinov (2009) afirmam que em determinada etapa de desenvolvimento da sociedade, encontram-sevalorizados(oudesvalorizados)determinado grupo de objetos. Pode-se afirmar, indiscutivelmente, que, no momento histórico atual, a escola pública vista como instituição, não como um objeto ou grupo de objetos, encontra-se claramente desvalorizada.

Essa afirmação tem sido reforçada em inúmeros trabalhos, dentre os quais destaco Frigotto (1993), que analisou a produtividade da escola improdutiva, e Patto (2010), que pesquisou a produção do fracasso escolar na escola pública.

Não se pode esquecer que essa situação de desvalorizaçãoéideológica, corresponde a uma determinada visão de mundo que é social e histórica, relacionada à manutenção da estratificação social e da desigualdade.

No próximo item, faço uma análise das entrevistas com os professores-participantes. $\mathrm{O}$ intuito dessa análise é o de resgatar os tópicos discursivos ${ }^{4}$ que emergem dos dizeres dos participantes desta pesquisa relativos à escolha e à realização profissional e ao ensinar-aprender inglês na escola pública. Partindo da principal categoria de análise utilizada, o organograma abaixo ilustra os tópicos e subtópicos discutidos a partir das análises das entrevistas.
${ }^{4}$ Os tópicos discursivos podem ser entendidos como "aquilo acerca do que se está falando" (FÁVERO, 2001, p. 38). Segundo Fávero (2001), o tópico discursivo é antes de tudo uma questão de conteúdo estando na dependência de um processo colaborativo que envolve os participantes do ato interacional. $\mathrm{O}$ tópico é, assim, uma atividade construída cooperativamente, isto é, há uma correspondência - pelo menos parcial - de objetivos entre os interlocutores. 


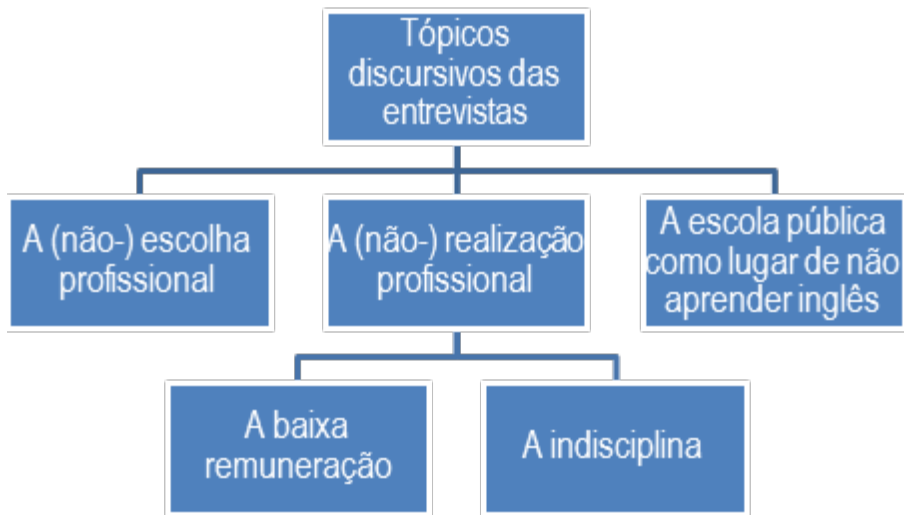

Figura 1: Entrevistas - Tópicos discursivos

\section{Entrevistas}

\subsection{A (não-) escolha profissional}

No trecho da entrevista inicial destacado abaixo, o professor Rui explica a sua escolha pelo curso de Letras.

PR: Inclusive eu dou aula de português em São Bernardo e a professora de Português foi minha professora de inglês no ensino médio. Ela não marcou nada. Não aprendi nada com ela. Tanto que eu ia fazer Filosofia na faculdade. Eu só fiz Letras porque era mais barato na faculdade. $\mathrm{O}$ professor de Filosofia me marcou. Por caminhos tortuosos eu acabei entrando em Letras porque me falaram que Filosofia é só pra padre e seminarista. É que eu tinha um professor muito legal de Filosofia. Muito legal. Ele tocava violão na sala. Levava coisas absurdas, levava cebola para ver se a gente chorava. (FERNANDES, 2011, p. 59)

Percebe-se que Rui não tinha como primeira opção o curso de Letras. Os dados apontam para a nãoescolha da profissão docente, Rui havia escolhido outra profissão e acabou tornando-se professor.

O próximo trecho trata da escolha profissional da professora Ana. 
PA: Na verdade eu escolhi ser professora não foi porque eu queria ser professora, não foi porque eu queria, não é uma coisa que eu sempre pensei, eu quero ser professora. Uma coisa que acabou vindo por conta de que eu queria usar o inglês. E também devido a eu estar no interior, no interior não existem inúmeras profissões que eu posso usar o inglês. No interior eu não podia dizer, eu vou optar pela área empresarial e vou usar o inglês.

PP: Aí você foi fazer Letras?

PA: Logo em seguida eu fui fazer Letras.

PP: Aqui ou no interior?

PA: No interior, numa cidade chamada Vista Alegre. Aí no primeiro ano de faculdade, a diretora da escola onde eu estudava me convidou para eu dar aula no curso onde eu estudava. Aí eu comecei, eu comecei a dar aula de inglês, eu tinha 18 anos. Eu nem era professora ainda, entrei de gaiata. E dali pra cá eu continuei sempre trabalhando com isso, só aula de inglês. Teve um período que eu também dei aula de espanhol. O que eu gosto mesmo é do idioma. Até é duro, só entre nós, nem sei assim hoje em dia se eu me sinto tão realizada. Às vezes eu olho assim e eu penso, até quando eu vou conseguir sala de aula. Eu acho que tá difícil. (FERNANDES, 2011, p. 59)

Percebe-se que Ana não pretendia tornarse professora de inglês, apesar de afirmar que gosta do idioma. Tanto a trajetória profissional de Rui como a de Ana foram marcadas pela não-escolha. Os participantes não realizaram verdadeiras escolhas profissionais, mas optaram dentre as alternativas que lhes eram possíveis.

Bastos (2005), em pesquisa realizada com jovens egressos do ensino médio público, conclui que os determinantes socioeconômicos representam o principal obstáculo para a concretização das opções profissionais dos sujeitos. A autora afirma que entre a 
escolha profissional realizada e a efetivação da mesma, há um caminho repleto de fatores condicionantes que podem interferir na realização do curso ou da profissão desejada. A necessidade de trabalhar, a falta de recursos para pagar um cursinho pré-vestibular ou uma faculdade, a impossibilidade de concorrer com igualdade com alunos oriundos de classes economicamente favorecidas, podem ter um peso decisivo na concretização de suas escolhas.

Rui e Ana são egressos da escola pública. Na fala de Rui, aparece o fator descrito acima como determinante na escolha profissional, a falta de recursos para pagar a faculdade que ele havia escolhido. Há algo muito maior que permeia e condiciona a efetivação da escolha profissional: a realidade socioeconômica.

Para Bastos (2005), essa realidade não determina o destino do jovem economicamente desfavorecido, mas certamente reduz a probabilidade de atingir suas metas, ou mesmo força a modificação de suas escolhas, negando-as ou adaptando-as para obter maiores chances de se inserir no ensino universitário ou no mundo do trabalho. Fica evidente que existe sempre uma relação entre as escolhas (que aparentemente são individuais) e a totalidade representada pelo universo político, econômico e social no qual as individualidades estão inseridas.

Com relação à Ana, tendo em vista a mudança de cidade, ela teve que adaptar suas escolhas à realidade encontrada na cidade do interior. Mesmo não se sentindo realizada como professora, continua exercendo a atividade docente. Sobre esse aspecto, Bastos (2005) afirma que a maioria dos jovens entrevistados para a sua pesquisa gostaria de realizar outro tipo de trabalho. Dos seis entrevistados, quatro alegaram gosto pessoal por outra área, ou seja, se pudessem realmente escolher, certamente estariam trabalhando em outra função. 
A escolha de Ana pode ser considerada uma falta de opção, uma reação à realidade encontrada na cidade no interior. Apesar de estar vivendo atualmente em uma grande cidade, onde aparentemente teria maiores oportunidades de fazer outra escolha, Ana acomoda-se.

Lapo e Bueno (2003) realizaram estudo com professores da rede pública estadual de São Paulo e afirmam que a acomodação é entendida como o distanciamento da atividade docente mediante condutas de indiferença a tudo que ocorre no ambiente escolar, ou de um tipo de inércia, no sentido de buscar inovações e melhorias no ensino, e um não envolvimento com o trabalho e com os problemas cotidianos da escola.

Segundo Lapo e Bueno (2003), muitos professores não chegam a abandonar definitivamente o trabalho, entretanto, recorrem a mecanismos de evasão. $O$ adiamento do abandono definitivo de um trabalho que não é mais fonte de prazer e equilíbrio acaba por gerar diferentes mecanismos de evasão. Tais mecanismos, que se caracterizam por um distanciamento físico ou psicológico do trabalho, são nomeados de abandonos temporários e abandonos especiais. $\mathrm{O}$ abandono temporário concretiza-se por meio de faltas, licenças curtas e licenças sem vencimentos. A acomodação é um tipo de abandono especial e muitos professores que vivenciam esse distanciamento da atividade docente ou de inércia, nunca deixarão seus empregos. Não há na acomodação o distanciamento físico, uma vez que o professor comparece à escola, ministra as aulas, cumpre as obrigações burocráticas, porém executa essas atividades dentro de um limite que representa o mínimo necessário para manter-se no emprego.

Características tanto da acomodação como do abandono ficam claras em outros momentos das entrevistas. 


\subsection{A (não-) realização profissional \\ 2.2.1 A baixa remuneração}

O professor Rui, no trecho destacado abaixo da entrevista menciona a questão da remuneração.

PP: Quantas horas você trabalha?

PR: 26 horas semanais aqui. 20 à noite. 46 horas em sala.

PP: Você tem pouco tempo para olhar o material e planejar?

PR: No meu caso sim, não é falta de vontade. Eu não sou do tipo que deixa para lá. Pelo contrário.

PP: Eu entendi.

PR: É que eu faço outras coisas. Eu tenho que buscar outras fontes para ganhar um bom salário. Eu não consigo chegar em casa e pensar em aula. (FERNANDES, 2011, p. 62)

Rui deixa clara a necessidade de buscar outras fontes de renda para garantir um melhor salário ao final do mês. A baixa remuneração dos professores de inglês da rede pública estadual na cidade de São Paulo aparece como um fator preponderante de insatisfação, segundo outras investigações. Nesse contexto, Sousa (2006) afirma:

Os levantamentos desta pesquisa indicam que, nos dias de hoje, a baixa remuneração dos professores, especialmente daqueles que trabalham em escolas públicas, é um dos fatores que mais parece causar descontentamento em relação à profissão. (SOUSA, 2006, p. 16)

Lapo e Bueno (2003) entrevistaram 158 exprofessores da rede pública que pediram exoneração no estado de São Paulo no período de 1990 a 1995. A baixa remuneração é citada por 17 dos 29 dos ex-professores 
que responderam ao questionário proposto pelas pesquisadoras com o objetivo de investigar os motivos para a exoneração.

Em virtude da baixa remuneração, Rui e muitos professores da rede pública têm um ou mais empregos para poderem, assim, garantir uma melhor renda ao fim do mês. Esse acúmulo de empregos resulta em uma sobrecarga de trabalho.

Silva Júnior, (1990 apudPAPARELLI, 2009, p. 23), descreve o professor como um trabalhador sem local de trabalho, uma vez que os trabalhadores da escola pública distribuem sua jornada por diferentes locais, reduzindo, consequentemente, seu tempo de permanência diária em cada lugar. Essa dispersão dos locais de trabalho implica desde logo a inviabilização de qualquer projeto organizacional ou político-pedagógico. $\mathrm{O}$ que ocorre de fato é que o professor da escola pública, para garantir um salário melhor, precisa de mais de um emprego e a dispersão acaba por gerar uma sobrecarga de trabalho. Isso dificulta a dedicação do professor ao planejamento das aulas, como Rui afirma, "não consigo chegar em casa e pensar em aula".

Além disso, a sobrecarga de trabalho contribuiria para o chamado mal-estar docente, termo cunhado por Esteve (1999), para designar o conjunto de dificuldades e constrangimentos profissionais que afetam o trabalho dos professores. Esteve (1999) aponta que o mal-estar docente é um fenômeno social do mundo ocidental, desencadeado por uma multiplicidade de fatores e alimentado tanto pela escola como pela comunidade e sociedade em geral. Alguns aspectos se mostram relevantes para caracterização desse fenômeno. Primeiramente, a sobrecarga de trabalho; depois, um sentimento de inutilidade em relação ao trabalho que realizam e também, é claro, os baixos salários (ESTEVE, 1999). 
O mal-estar docente desencadearia uma crise de identidade, em que o professor passaria a se questionar sobre a sua escolha profissional e o próprio sentido da profissão. O tema da (não-) escolha profissional é trazido por muitos autores, como Frigotto (1995), Lapo e Bueno (2003) e Sousa (2006) e vem à tona no discurso dos professores entrevistados.

A baixa remuneração e a sobrecarga, entretanto, não aparecem isoladamente como únicos fatores de insatisfação profissional. Ana demonstra que outro fator de grande insatisfação para ela está relacionado ao comportamento dos alunos em sala de aula. Analiso essa questão abaixo e procuro demonstrar que a conduta dos alunos não pode ser analisada de maneira isolada, sem considerar o procedimento do professor e as aulas. Apontar também a importância do contexto social e econômico do qual os professores fazem parte para compreensão das dificuldades com as quais eles se deparam.

\subsubsection{A indisciplina}

Nesse trecho da entrevista, ao ser questionada sobre a língua que é falada com os alunos em sala de aula, a professora menciona a questão da indisciplina.

PP: Você procura trabalhar a parte oral?

PA: Bem pouco. É o que a professora do curso de mestrado fala. Eu preciso me investigar, eu sou fluente, por que eu não falo inglês na sala?

PP: O que você acha?

PA: Todo ano eu falo, eu penso, é esse ano. Eu acho que nas vezes que eu falo, muitas vezes eu tenho que ficar repetindo em português. É mais desgastante as vezes que eu tenho que ficar repetindo em português. Acho que eu tenho um pouco de vergonha. Não é que eu não falo porque eu não sei. Eu não consigo introduzir. Simplesmente eu não consigo. 
PP: Você acha que tem a ver com os alunos ou com você?

PA: Acho que tem a ver comigo. Eu acho que a parte dos alunos é essa. Essa indisciplina que a gente tem. Você precisa ficar chamando a atenção e ficar pedindo para que eles te ouçam, eu acho que isso atrapalha um pouco. Mas eu acho que é comigo mesmo. (FERNANDES, 2011, p. 64)

Ela demonstra que outro fator de grande insatisfação está relacionado à indisciplina e à bagunça. Embora apenas mencione que a indisciplina "atrapalha um pouco" as suas aulas, em todos nossos encontros a indisciplina aparece como um fator preponderante de insatisfação. Aquino (1998) acredita que a indisciplina pode ser uma resposta clara dos alunos ao abandono do professor de suas funções docentes. Aquino (1998) afirma que "como em todas as relações sociais/institucionais, na relação pedagógica existe um contrato implícito" (AQUINO, 1998, p. 8). Segundo ela, os alunos têm uma clareza impressionante quanto a essas balizas contratuais do encontro pedagógico. Sabem reconhecer quando o professor está exercendo suas funções, cumprindo seu papel e também percebem quando o professor abandona seu posto. Desse modo, a indisciplina pode ser compreendida como um termômetro da relação do professor com seu campo de trabalho, com sua função.

A questão da indisciplina como uma resposta àquilo que acontece dentro da sala de aula também é tratada por Sposito e Galvão (2004), em pesquisa realizada entre 2001 e 2002 com jovens estudantes de escolas públicas na cidade de São Paulo. Segundo as autoras, "as reiteradas queixas dos professores quanto à dificuldade de ensinar, dentre outras razões pela suposta falta de motivação, indisciplina e insubordinação dos jovens" (SPOSITO e GALVÃO, 2004, p. 374), contrasta com a voz dos próprios alunos, que assinalam os problemas de aprendizagem como os mais importantes. 
Desse modo, embora se sinta insatisfeita em relação à indisciplina, ela menciona o interesse que determinadas atividades despertam nos alunos.

PP: Você disse que eles tiveram um interesse maior quando você trouxe a biografia do Daniel Radcliffe, aquele que faz o Harry Potter?

PA: Teve interesse quando eu trouxe a biografia do Daniel Radcliffe. Hoje por eu ter o material eu não faço mais isso com frequência, isso tá me deixando frustrada. Eu não tô trazendo por duas razões. Primeiro falta de tempo, o material é muito extenso e infelizmente, por comodidade. $\underline{\text { Se eu tenho um material ali pronto é mais fácil }}$ do que ter que assistir a um filme, escolher uma cena. (FERNANDES, 2011, p. 65)

Apesar de ressaltar que a indisciplina dos alunos "atrapalha um pouco" as suas aulas, Ana reconhece que não se dedica muito ao preparo das aulas. Poucas vezes, ao longo do ano, procurou trazer atividades que propiciassem um maior envolvimento dos alunos.

A indisciplina pode estar relacionada à acomodação da professora que não ministra aulas que propiciariam um maior envolvimento de seus alunos, com atividades mais interessantes e intelectualmente desafiadoras.

Além disso, no material fornecido pela Secretaria de Educação do Estado de São Paulo, existem sugestões de inúmeras atividades interessantes e que poderiam ser utilizadas pelos professores. Não haveria necessidade de "assistir a um filme, escolher uma cena" como ela afirma. Ela reconhece a sua acomodação, que corresponderia a um distanciamento da atividade docente, a um não envolvimento quando se trata de buscar melhorias ou inovações no ensino.

No próximo item, analiso um último dado que considero relevante para este artigo. Tanto nas falas do 
professor como da professora a escola pública aparece como um local de não-aprendizagem do inglês.

\subsection{A escola pública como o lugar de não aprender inglês}

É interessante notar como ambos abordam a questão da escola pública como local de aprendizagem de inglês.

PP: Você acha que eles vêm com a ideia de que não se aprende inglês na escola, só no curso particular?

PR: Com certeza. Para você ter uma ideia, o curso de Inglês que eu fiz foi o da Cultura Inglesa, teve aquela oportunidade, de graça, só na parte da conversação. $\underline{O}$ que eu penso sinceramente é que se o professor de inglês conseguir despertar o interesse dos alunos, se o professor conseguir fazê-los gostar, se o professor conseguir fazê-los querer entrar num curso eu acho ótimo. Não interessa o curso. (FERNANDES, 2011, p. 66)

Depreende-se do trecho que o local onde a aprendizagem de inglês ocorre não é a escola pública. $\mathrm{O}$ discurso do professor revela nitidamente o abandono descrito, pois o que importa para ele é conseguir despertar o interesse dos alunos para que estudem inglês em um curso particular, fora da escola pública. Dessa forma ele se distancia completamente da tarefa de ensinar a língua inglesa.

No trecho destacado, Ana trata da questão da aprendizagem de inglês na escola pública.

PP: Como você acha que eles vêm o ensino de inglês aqui na escola? Você acha que existe a ideia de que só aprende inglês fora da escola? 
PP: Você tem alunos que fazem inglês fora?

PA: Tenho poucos, aí as crianças falam, ele estuda fora, por isso que ele sabe. Tá aí, né. Eu queria mudar isso, é complicado.

PP: O que é aprender inglês na escola?

PA: Não é muito claro. Eles não vêm função pra quase nada que eles aprendem na escola, mas tem função, a gente ainda não achou uma forma de mostrar isso pra eles. (FERNANDES, 2011, p. 67)

Para ela os alunos não vêm função para quase nada que aprendem na escola. Aspecto semelhante aparece no trabalho de Baghin-Spinelli (2002), que investigou as identidades dos futuros professores de inglês nos cursos de formação de professores. Segundo a autora, o inglês da escola pública é material descartável, sem importância, que não serve para nada enquanto o inglês da escola de idiomas é o inglês oralizado. As escolas de idiomas aparecem nas falas dos futuros professores de inglês como lugares onde realmente "se aprende a língua inglesa" (BAGHIN-SPINELLI, 2002, p. 122).

Destaco que Rui e Ana, ao contrário de muitos professores de inglês que atuam em escolas públicas, são fluentes no idioma. Estariam mais bem preparados que muitos professores que atuam na rede pública e teriam conhecimentos suficientes para trabalhar a oralidade com os alunos. No entanto, não o fazem.

Ana afirma que trabalha "bem pouco" a parte oral. Esse fato foi observado nas aulas de Ana e Rui que assisti e que constam da pesquisa de mestrado que desenvolvi a partir das entrevistas e aulas dos dois professores. Nas aulas assistidas, pude observar que o inglês não é utilizado nem mesmo para interações mais simples com os alunos, como nos momentos em que o professor chega à classe e vai embora. 
Conforme a perspectiva teórica adotada, a ideologia determina os discursos dos falantes, no caso, dos dois professores. A partir da análise, compreendese que as ideologias dos professores (irrefletidas ou não) corroboram a idéia difundida na nossa sociedade de que não se aprende inglês na escola pública.

\section{Conclusão}

Conforme a perspectiva teórica adotada, o comportamento de Ana e Rui, estão relacionados a uma determinada visão de mundo ou ideologia. Nesse sentido, Apple (2006) esclarece que a falta de envolvimento dos professores com seu trabalho, comportamento que o autor chama de "negligente" e que foi observado nos participantes desta pesquisa, deve ser entendido em termos de uma padronização mais ampla de relações sociais e econômicas na estrutura social da qual os professores e a própria escola são parte. Em outras palavras, as ideologias ou visões dos professores devem ser entendidas a partir de uma perspectiva mais ampla, na qual aspectos históricos, sociais e econômicos são levados em conta. Partindo-se dessa perspectiva, a escola não pode ser retirada de seu ambiente, que é o de uma relação muito maior e mais poderosa com instituições econômicas e políticas que lhe conferem significado. Nessa esfera, Apple (2006) destaca:

[...] meu argumento não deve ser visto como uma declaração contra determinada escola ou qualquer grupo de professores Ao contrário, quero apontar a necessidade de os educadores verem o quanto os professores estão "encapsulados" em um contexto social e econômico que necessária e frequentemente produz os problemas com que os professores se deparam e as limitações materiais de suas respostas. Esse contexto muito "externo" dá legitimação substancial para a alocação do tempo e energia dos professores e para os tipos de capital cultural engastados na própria escola (APPLE, 2006 p. 97). 
Os professores situam-se em um contexto social e econômico e não podem ser vistos "descolados" dessa realidade. Esse contexto legitima a postura de acomodação na qual se inscrevem os professores e contribui para um desenvolvimento cognitivo e vocacional que fortalece ou reforça os arranjos institucionais existentes (e em geral problemáticos) na sociedade (APPLE, 2006).

Michael Apple, ao analisar sua própria atuação como professor e educador de professores e administradores, amplia a discussão.

Culpar os professores, incriminar os indivíduos, não ajudava em nada. Analisar como, e especialmente por quê, a instituição faz o que faz, de modo que se pudesse ir além dessas ações individuais, parecia mais adequado (APPLE, 1989, p.38).

Neste artigo, procurei compreender como as visões sobre o ensino-aprendizagem de inglês se manifestam em seus discursos (irrefletidos ou não) elegitimam uma postura ideológica presente na nossa sociedade. Os professoresparticipantes, mesmo fluentes no idioma e portanto com maiores condições de ensinarem o inglês, não acreditam que a escola pública seja o lugar onde se aprende inglês. Em uma perspectiva mais ampla, a postura adotada pelos professores contribui para a reprodução da desigualdade existente na sociedade, na qual os alunos da escola pública de fato recebem menos do que poderiam, ao menos no que diz respeito à aprendizagem do inglês como língua estrangeira. A escola torna-se um local privilegiado, onde a desigualdade encontrada na sociedade não é apenas reproduzida, mas também é produzida.

Acredito que para que os alunos da escola pública tenham reais oportunidades de aprender inglês é preciso que haja uma mudança nas ideologias dos professores. Faz-se então necessária a criação espaços de reflexão 
nas escolas além de políticas públicas que contemplem a valorização da carreira. Nos espaços de reflexão organizados em forma de reuniões ou encontros, os professores em-serviço teriam a oportunidade de refletir sobre suas ideologias ligadas ao ensinar-aprender inglês na escola pública. À medida que as ideologias venham à tona, é possível um confronto do professor com o que pensa e pratica em sala de aula. Esse seria um passo para a mudança.

No entanto, sem políticas públicas de valorização da profissão, incluindo a valorização salarial, o ingresso na carreira torna-se muito pouco atraente para os jovens. A desvalorização da profissão é uma causas da situação lastimável em que a escola pública se encontra nos dias de hoje. A desvalorização está presente na mídia, nos discursos que circulam na sociedade, nos discursos dos professores e nos baixos salários. Com esse panorama em vista, como podemos esperar uma escola que ofereça um ensino de inglês que possa contribuir para formação de alunos que possam agir no mundo global, no mundo que fala inglês? 


\section{Referências}

AMORIM, M. O Pesquisador e seu outro. São Paulo: Musa, 2004.

APPLE, M. Ideologia e Currículo. Trad. Vinicius Figueira. 3. ed. Porto Alegre: Artmed, 2006.

. Educação e Poder. Trad. Maria Cristina Monteiro.

Porto Alegre: Artmed, 1989.

AQUINO, J. G. A indisciplina e a escola atual. Rev. Fac. Educ., São Paulo, v. 24, n. 2, 1998, p.181-204.

BAGHIN-SPINELLI, D.C. Ser Professor (Brasileiro) de Língua Inglesa: Um Estudo dos Processos Identitários na Práticas de Ensino. Tese de Doutorado. Campinas/SP, Instituto de Estudos da Linguagem, Universidade Estadual de Campinas, 2002.

BAKHTIN, M. M. Os gêneros do discurso In: Estética da Criação Verbal. Trad. Paulo Bezerra. 5. ed. São Paulo: Martins Fontes, 2006 [1951-53], p. 261-306.

BAKHTIN, M. M. Problemas da Poética de Dostoievski. Trad. Paulo Bezerra. 4. ed. Rio de Janeiro: Forense Universitaria, 2008 [1963].

BAKHTIN, M. M./ MEDVEDEV, P. N. The formal method in literary scholarship: a critical introduction to sociological poetics. Trad. Albert J. Wehrle. Maryland: Johns Hopkins Press, 1991 [1928].

BAKHTIN, M. M. (VOLOCHINOV, V. N.) Marxismo e filosofia da linguagem: problemas fundamentais do método sociológico na ciência da linguagem. Trad. Michel Lhanud e Yara Frateschi Vieira. 13. ed. São Paulo: Hucitec, 2009 [1929].

BARCELOS, A. M. F. Narrativas, crenças e experiências de aprender inglês. Linguagem e Ensino, v. 9, n. 2, 2006. p. 145175. 
BASTOS, J. C. Efetivação de Escolhas Profissionais de Jovens Oriundos do Ensino Público: um Olhar sobre suas Trajetórias. Rev. bras. orientac. prof., São Paulo, v. 6, n. 2, 2005, p. 31-43.

BRAIT, B.; MELO, R. Enunciado/ enunciado concreto/ enunciação. In: BRAIT, B. (Org.) Bakhtin: conceitos-chave. São Paulo: Contexto, 2005. p. 61-78.

COX, M.I.P. e ASSIS-PETERSON, A.A. Inglês em tempos de globalização: para além de bem e mal. Caleidoscópio, v. 5, n. 1, 2007. p 5-14.

DIAS, M. H. M. O lugar do inglês na escola pública:(des) crenças de atores da escola e da comunidade. Dissertação de Mestrado. Cuiabá, MT. Universidade Federal de Mato Grosso. 2006.

ESTEVE, J.M. O mal-estar docente: a sala de aula e a saúde dos professores. Trad. Durley de Carvalho Cavicchia. Bauru, SP: EDUSC, 1999.

FARACO, C. A. Linguagem \& Diálogo: as ideias linguísticas do círculo de Bakhtin. São Paulo: Parábola Editorial, 2009.

FÁVERO, L. L. O tópico discursivo. In: Preti, D. (Org.) Análise de textos orais. São Paulo: Humanitas FFLCH/USP, 2001. p. 33-54.

FERNANDES, P. T. C. Ideologia e ensino-aprendizagem de inglês na escola pública. Dissertação de Mestrado, PUC-SP, 2011.

FRIGOTTO, G. A produtividade da escola improdutiva. Um (re)exame das relações entre educação e estrutura econômicosocial capitalista. São Paulo: Cortez, 1993.

FRIGOTTO, G. Educação e a crise do capitalismo real. São Paulo: Cortez, 1995.

LAPO, F. R. \& BUENO, B. O. Professores, Desencanto com a Profissão e Abandono do Magistério. In: Cadernos de Pesquisa, n.118, 2003, p. 65-68. 
MARX, K.; ENGELS, F. A ideologia alemã. Trad. Luis Claudio de Castro e Costa. 3. ed. São Paulo: Martins Fontes, 2007 [1933].

MIOTELLO, V. IdeoIogia. In: BRAIT, B. (Org.) Bakhtin: conceitos-Chave. São Paulo: Contexto, 2005. p. 167-177.

PAPARELLI, R. Desgaste mental do professor da rede pública de ensino: trabalho sem sentido sob a política de regularização do fluxo escolar. Tese de Doutorado. São Paulo. Instituto de Psicologia da Universidade de São Paulo. 2009.

PATTO, M. H. S. "Escolas cheias, cadeias vazias" nota sobre as raízes ideológicas do pensamento educacional brasileiro. Estud. Av. v. 21, n. 61, 2007. p. 243-255.

PATTO, M. H. S. A Produção do Fracasso Escolar. São Paulo: Casa do Psicólogo, 2010.

SANTOS, L. I. S. Crenças acerca da inclusão de lingua inglesa nas séries iniciais: quanto antes melhor? Dissertação de Mestrado. Cuiabá, MT. Universidade Federal de Mato Grosso. 2006.

SOUSA, R. M. Professores de inglês da escola pública: investigações sobre suas identidades numa rede de conflitos. Dissertação de Mestrado. São Paulo, Programa do Curso de Pós-Graduação em Estudos Linguísticos e Literários em Inglês. Universidade de São Paulo, 2006.

SPOSITO, M. P. \& GALVÃO I. A experiência e percepções de jovens na vida escolar na encruzilhada das aprendizagens: o conhecimento, a indisciplina, a violência. Perspectiva, Florianópolis, v. 22, n. 02, 2004. p. 345-380;

ZANDWAIS, A. Bakhtin/Voloshinov: condições de produção de Marxismo e filosofia da linguagem. In: BRAIT, B. (Org.) Bakhtin e o círculo. São Paulo: Contexto, 2009. p. 97-116.

Recebido em 28/02/2014 Aceito para publicação em 22/07/2014 